\title{
Comparison of Drug and Non-Drug Treatment Options of Fibromyalgia
}

\author{
Abdul Kader Mohiuddin* \\ Department of Pharmacy, World University of Bangladesh, Bangladesh
}

*Corresponding author : Abdul Kader Mohiuddin, Department of Pharmacy, World

University of Bangladesh, Bangladesh.

Received Date: August 05, 2019

Published Date: August 22, 2019

\begin{abstract}
There is no clear specific pathophysiological therapeutic target of fibromyalgia (FM) management. The management of this complex condition has thus perplexed the medical community for many years, and several national and international guidelines have aimed to address this complexity. Pain relieving pharmaceutical medications are generally connected with an assortment of unfriendly reactions, for example, constipation, urinary retention, nausea, sedation, respiratory depression, myoclonus, delirium, sexual dysfunction, and hyperalgesia. The challenge of achieving adequate pain control without adverse side effects further compounds the problem and provides rationale for seeking complementary medicine and nonmedicine alternatives.
\end{abstract}

Keywords: Fibromyalgia; Chronic noncancer pain; Neurofeedback; Cognitive behavioral therapy; Acceptance and commitment therapy; Inflammatory arthritis

Abbreviations: FM: Fibromyalgia; RA: Rheumatoid Arthritis; NSAIDs: Non-Steroidal Anti-Inflammatory Drugs; CNCP: Chronic Noncancer Pain; PEA: Palmitoylethanolamide; FODMAP: Fermentable Oligo-, Di-, Mono-saccharides And Polyols; EMG-BFB: Electroencephalography Biofeedback; CBT: Cognitive Behavioral Therapy; IL-6: Interleukin-6, TNF- $\alpha$ : Tumor Necrosis Factor Alpha; ACT: Acceptance And Commitment Therapy; HRQoL: Health-Related Quality of Life; WBV: Whole Body Vibration; EA: Electro-acupuncture; HBOT: Hyperbaric Oxygen Therapy; LLLT: Low-Level Laser Therapy; TENS: Transcutaneous Electrical Nerve Stimulation

\section{Short Communication}

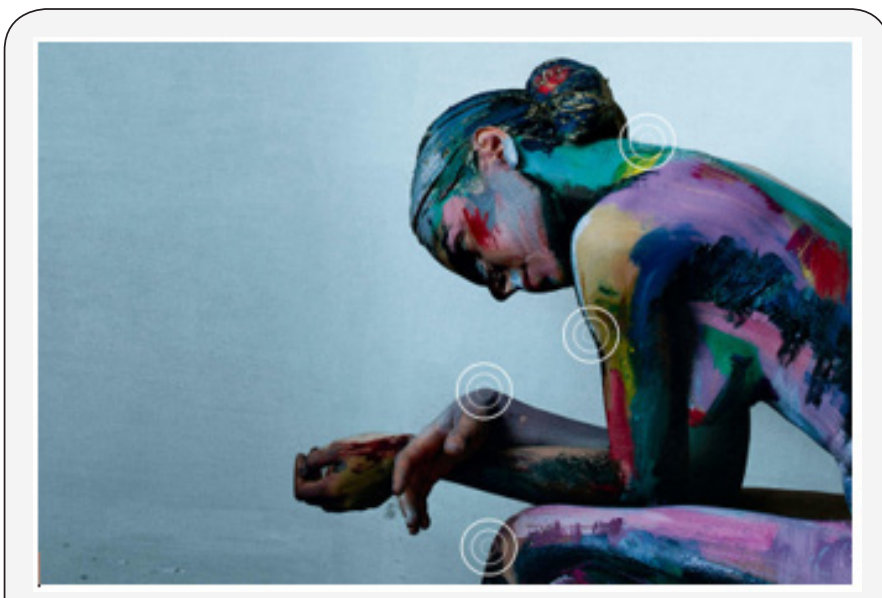

Figure 1: Perspectives on Living with Fibromyalgia [1].

Perceptions of people living with chronic illness change over time, contributing to health-related stress that necessitates coping skills. Self-efficacy operates as an important cognitive factor in the control of symptoms such as pain, with self-efficacy beliefs helping to explain many of the behaviors and disabilities of those with persistent symptoms (Figure 1).

Fibromyalgia (FM) is an idiopathic chronic condition that causes widespread musculoskeletal pain, hyperalgesia and allodynia, affecting $2.10 \%$ (a total of $4 \%$ female and $2-5 \%$ male) of the world's population, $2.3 \%$ of the European population, $2.4 \%$ of the Spanish population [2,3]. In France, work productivity loss contributed almost $90 \%$ of the total costs incurred by patients with FM, with an economic cost of 13000 million euros annually which is around $\$ 100$ billion in US $[2,4,5]$. Work disability was found to be $35 \%$ in US and Australia and 30\% reported in Canada due to FM [6]. FM is more common in women compared to men, with a ratio of $2: 1$ [7] or $3: 1$ [8], although other studies say $85 \%$ $90 \%$ FM patients are middle aged women $[9,10]$. 30-50\% of FM 
patients have anxiety and/or depression at the time of diagnosis [11], while patients have a lifetime history of depression (50-75\%) [12] and depressive disorders (13\%-63.8\%) [13]. Chronic tension type headache was endorsed by $50-80 \%$ of treatment-seeking FM patients $[7,14]$. FM is also common in $10-30 \%$ of patients with primary rheumatic diseases $[15,16]$. Rheumatic fever, neck pain, constipation, diarrhea, fatigue and notably insulin resistance are the most predictive symptoms of having future FM [4,17-20]. A nearly 75\% FM patients have comorbidity issues of pain-nonpain symptoms, psychological distress, social security and work disability [21]. FM patients incur direct costs approximately equal to RA patients, but visit more emergency physicians, physicians, and physical therapists [22]. Duloxetine, amitriptyline and pregabalin are among the most widely used medications with higher efficacy reported with duloxetine [23-26]. As the medical management of FM is often only partially successful, health professionals need to give patients sustained support to become expert, active selfmanagers $[27,28]$. Emerging data suggests that a common feature associated with treatment failure is pain arising from dysfunctions within the brain and spinal cord [29]. Also, long-term safety of conventional drugs is unknown [30].

NSAIDs are widely used in FM, despite being considered not to be effective [31,32]. Also, opioid users showed less improvement in pain-related interference with daily living, functioning, depression, and insomnia [33]. Evidence for effectiveness of cannabinoids in chronic noncancer pain (CNCP) is also limited [34] and but not in FM $[35,36]$, although strong monitoring is mandatory. Cytokines/ chemokines, lipid mediators, oxidative stress and several plasmaderived factors underlie the inflammatory state in FM [37]. Adding palmitoylethanolamide (PEA) to initial duloxetine + pregabalin therapy improved the outcome of FM [38]. Schweiger et.al, 2019 demonstrated ultra-micronized PEA treatment was well-tolerated among FM patients with GI symptoms (diarrhea, dyspepsia, bloating, constipation, vomiting) reported in nearly $14 \%$ patients [39]. Herbal medicine includes over 2000 different medicinal substances with 80-100 commonly used for the treatment of FM [40]. Studies show that 70\% FM patients tried nutritional supplements to control FM symptoms, although none of them found to be consistently effective [41].

Transient, burning and pricking, skin irritation, dizziness, nausea, dry mouth, drowsiness, constipation and insomnia were some of the side effects associated with herbal medicines [42]. A nearly 70\% German FM patients used thermal baths, $35.2 \%$ use alternative interventions such as homeopathy, dietary supplements, and $18.4 \%$ use meditative exercises such as yoga or Tai chi [43]. Research has suggested that traditional Eastern practices such as tai chi, qigong and yoga can relieve FM symptoms, the same practices found to be effective adjunct for Anxiety, MDD and insomnia management [44-47]. Low FODMAP was found be effective in QOL, quality of sleep, anxiety and depression and inflammatory biomarkers in FM patients [48-53]. In general, exercise and psychoeducational approaches have the greatest evidence of efficacy among non-pharmacological therapies, but they need to be tailored to the individual [54]. Electroencephalography biofeedback (EMG-BFB) or Neurofeedback might reduce pain intensity, improve attention and QoL more successfully than other psychological or multicomponent programs [55-57]. Cognitive behavioral therapy (CBT) interventions may slow or reverse cortical gray matter atrophy, reduces circulating proinflammatory cytokines (IL-6, IL-8, and TNF- $\alpha$ level) of fibromyalgia patients, pain symptoms and pain perceptions, helps FM patient having fear of pain, anxiety, depression and insomnia [58-62]. CBT and specialized neuromuscular exercise intervention offer stronger treatment benefits than CBT alone in juvenile FM [63].

Significant differences regarding trait anxiety, sleep quality, and tenderness at some points along with alleviation of pain intensity, fatigue and depression reported with audio-recorded guided imagery (one component of CBT) relaxation on people with FM [64-67]. Fear of pain leads to depression, social isolation, disability or reduced participation in daily life activities [68]. Fear avoidance beliefs alleviates inactivity/disability [69,70], a $20-30 \%$ improvement in pain disability reported by Palstam et.al, 2016 [71]. The goal within acceptance and commitment therapy (ACT) is to reduce the dominance of pain in person's life through increased psychological flexibility [72]. A significant change in psychological inflexibility, self-efficiency, pain-related functioning, FM impact (due to improved pain acceptance) reported with ACT [73-75]. However, ACT was not more effective than the "active" comparison conditions (e.g., CBT) in chronic pain management [76]. Exercise is effective for the management of fibromyalgia syndrome for up to 6 months. individualized resistance exercise was followed by changes in IGF-1 and leptin, reduced pain, fatigue and improved muscular strength [8,77-79], however, poor concordance to exercise interventions and adherence reported by Álvarez-Gallardo et.al, 2019 [80]. So, the therapeutic validity of exercise intervention programs in fibromyalgia is low. Mixed exercise probably improves HRQoL, physical function, and fatigue [81]. Aerobic exercise may slightly decrease pain intensity, may slightly improve physical function, and may lead to little difference in fatigue and stiffness [82]. Whole body vibration (WBV) to an exercise protocol positive effects on pain intensity [83-85]. Although, Dong et.al, 2019 reported no significant relieve from chronic musculoskeletal pain compared with the traditional treatment [86].

Acupuncture therapy is an effective and safe treatment for patients with FM, it was more effective in relieving pain in both the short and long term compared with conventional medication [8789]. Changes in serum serotonin and SP levels may be a valuable explanation for acupuncture mechanisms in FM treatment [90]. People with FM may consider using electro-acupuncture (EA) alone or with exercise and medication [91]. Physiotherapy and acupuncture, both are effective, not found to be more beneficial than the other, longer post-treatment follow-up may help determine the superior treatment option [92]. El-Shewy et.al, 2019 and Atzeni et.al, 2019 reported that Hyperbaric oxygen therapy (HBOT) has been utilized and has recently shown promising effects in the management of FM $[93,94]$. HBOT in FM induces changes in 
cortical excitability and a secondary reduction in pain and muscle fatigue, improved the ability of the central motor command to generate the same effort (MVC) with fewer recruited fibers [95]. Tirelli et.al, 2019 reported significant improvement without side effects with ozone therapy [96]. Mindfulness can be conceptualized as a primarily cognitive practice; in that it involves the purposeful control of attention to foster nonjudgmental awareness of the present moment [97]. Higher mindfulness is associated with less pain interference, lower impact of fibromyalgia, and better psychological health and quality of life in people with FM [98].

Mindfulnessmeditation may providean effectivecomplementary treatment when combined with other reliable techniques (exercise, CBT) [99]. An average 12-minute exposure to a therapy dog reduces anxiety in 34\% of fibromyalgia patients, together with reductions in pain and improvements in mood [100]. Massage therapy may improve pain, anxiety, depression, and sleep disturbance by complex interplay of both physical and mental modes of action $[101,102]$. de Oliveira et.al, 2018 reported improved QoL, reduced perceived stress index and pain with massage therapy [103]. Honda et.al, 2018 discussed several physical-agent modalities like lowlevel laser therapy (LLLT), thermal therapy, electromagnetic field therapy, and transcutaneous electrical nerve stimulation (TENS) for FM management. Thermal therapy and LLLT had a partial effect on pain relief in FM patients [104]. TENS has short-term efficacy in relieving symptoms of fibromyalgia while the stimulator is active [105]. There is no high-quality evidence to support or refute the use of TENS in FM [106]. Exercises combined with TENS might be useful due to quick myalgic pain relief in the treatment of fibromyalgia in everyday practice [107]. Thermal therapy combining sauna therapy and underwater exercise improved the QoL as well as the pain and symptoms of FM [108]. Spa therapy comprises a broad spectrum of therapeutic modalities including hydrotherapy, balneotherapy, physiotherapy, mud-pack therapy, and exercise. It can represent a useful backup to pharmacologic treatment of FM [109]. Adding water therapy to the usual care for FM patients is cost-effective for both healthcare and societal costs [22].

Nascimento et.al, 2015 suggested that cyclodextrin-complexed Ocimum basilicum leaves essential oil increases Fos protein expression in the CNS and might be a therapeutic alternative to FM management [110]. Patients severely affected by fibromyalgia can obtain short-term improvements following topical capsaicin 0.075 $\%$ treatment three times daily for 6 weeks [111]. Touch therapy, aromatherapy, reflexology, chiropractic and massage therapies and hypnotherapy can be effective in improving QoL in FM patients [112115]. Clinical trials of pharmacological and nonpharmacological therapies have shown that improving sleep quality can reduce pain and fatigue in FM [116]. Music acts as a sleep aid, reduces the pain perception and FM-associated sleep disturbances [117,118]. Low to moderate intensity endurance and strength training are strongly recommended in FM patients [119]. Strength training reduces pain, fatigue, number of tender points, depression, and anxiety, with increased functional capacity and QoL [120]. Exercise activates the endogenous opioid and adrenergic systems but does not consistently mitigate pain in FM patients [121]. Roitenberg et.al, 2019 recommended special training for the physiotherapists treating FM to reduce their uncertainty and role ambiguity [122]. Perceptual surfaces are efficacious in treating female patients with FM, similar to physical group exercises, improving physical function and mitigating pain [121]. Clinical interventions such as patient education on central pain management could lead to promising results, but the effectiveness of education in the reduction of the main symptoms is limited [123]. In comparison to inflammatory arthritis (IA), it can seem ill defined with no clear understanding of the pathology and therefore no specific targeted treatment. Treatment should be multidisciplinary and individualized with close attention to the patient's symptoms. A coordinated multidisciplinary team approach including physicians, mid-level practitioners, nursing staff, and where needed, pharmacists and physical therapists will produce the best results.

\section{Acknowledgement}

I'm thankful to Dr. Fabiola Atzeni, Associate Professor, Rheumatology Unit, University of Messina, Italy for her valuable time to audit my paper and for his thoughtful suggestions. I'm also grateful to seminar library of Faculty of Pharmacy, University of Dhaka and BANSDOC Library, Bangladesh for providing me books, journal and newsletters.

\section{Conflict of Interest}

The author declares that he has no competing interests.

\section{References}

1. Taylor AG, Adelstein KE, Fischer-White TG, Murugesan M, Anderson JG (2016) Perspectives on Living with Fibromyalgia. Glob Qual Nurs Res.

2. Cabo-Meseguer A, Cerdá-Olmedo G, Trillo-Mata JL (2017) Fibromyalgia: Prevalence, epidemiologic profiles and economic costs. Med Clin (Barc) 149(10): 441-448.

3. Muraleetharan D, Fadich A, Stephenson C, Garney W (2018) Understanding the Impact of Fibromyalgia on Men: Findings from a Nationwide Survey. Am J Mens Health 12(4):952-960.

4. AK Mohiuddin (2019) Non-drug pain management: opportunities to explore. BiomedGrid LLC, USA.

5. Pappolla MA, Manchikanti L, Andersen CR, Greig NH, Ahmed F, et al. (2019) Is insulin resistance the cause of fibromyalgia? A preliminary report. PLoS One 14(5): e0216079.

6. Palstam A, Mannerkorpi K (2017) Work Ability in Fibromyalgia: An Update in the 21st Century. Curr Rheumatol Rev 13(3): 180-187.

7. D’Agnelli S, Arendt-Nielsen L, Gerra MC, Zatorri K, Boggiani L, et al. (2019) Fibromyalgia: Genetics and epigenetics insights may provide the basis for the development of diagnostic biomarkers. Mol Pain.

8. Sosa-Reina MD, Nunez-Nagy S, Gallego-Izquierdo T, Pecos-Martín D, Monserrat J, et al. (2017) Effectiveness of Therapeutic Exercise in Fibromyalgia Syndrome: A Systematic Review and Meta-Analysis of Randomized Clinical Trials. Biomed Res Int.

9. Ghavidel-Parsa B, Bidari A, Amir Maafi A, Ghalebaghi B (2015) The Iceberg Nature of Fibromyalgia Burden: The Clinical and Economic Aspects. Korean J Pain 28(3): 169-176.

10. Arout CA, Sofuoglu M, Bastian LA, Rosenheck RA (2018) Gender Differences in the Prevalence of Fibromyalgia and in Concomitant Medical and Psychiatric Disorders: A National Veterans Health Administration Study. J Womens Health (Larchmt) 27(8): 1035-1044. 
11. Bhargava J, Hurley JA (2019) Fibromyalgia. StatPearls [Internet] Treasure Island (FL).

12. Kaltsas G, Tsiveriotis K (2017) Fibromyalgia. Feingold KR, Anawalt B, Boyce A, et al., editors. Endotext [Internet]. South Dartmouth (MA).

13. Galvez-Sánchez CM, Duschek S, Reyes Del Paso GA (2019) Psychological impact of fibromyalgia: current perspectives. Psychol Res Behav Manag 12: $117-127$.

14. Marcus DA, Bernstein C, Rudy TE (2005) Fibromyalgia and headache: an epidemiological study supporting migraine as part of the fibromyalgia syndrome. Clin Rheumatol 24(6): 595-601.

15. Phillips K, Clauw DJ (2013) Central pain mechanisms in the rheumatic diseases: future directions. Arthritis Rheum 65(2): 291-302.

16. Tan AC, Jaaniste T, Champion D (2019) Chronic Widespread Pain and Fibromyalgia Syndrome: Life-Course Risk Markers in Young People. Pain Res Manag.

17. in elderly women(2013) Healio.

18. WebMD (2018) 10 Rheumatoid Arthritis Symptoms You Shouldn't Ignore. Rheumatoid Arthritis.

19. Rowe PC, Underhill RA, Friedman KJ, Gurwitt A, Medow MS, et al. (2017) Myalgic Encephalomyelitis/Chronic Fatigue Syndrome Diagnosis and Management in Young People: A Primer. Front Pediatr 5: 121.

20. Pappolla MA, Manchikanti L, Andersen CR, Greig NH, Ahmed F, et al. (2019) Is insulin resistance the cause of fibromyalgia? A preliminary report. PLoS One 14(5): e0216079.

21. Walitt B, Nahin RL, Katz RS, Bergman MJ, Wolfe F (2015) The Prevalence and Characteristics of Fibromyalgia in the 2012 National Health Interview Survey. PLoS One 10(9): e0138024.

22. Zamunér AR, Andrade CP, Arca EA, Avila MA (2019) Impact of water therapy on pain management in patients with fibromyalgia: current perspectives. J Pain Res 12: 1971-2007.

23. Bidari A, Moazen-Zadeh E, Ghavidel-Parsa B, Rahmani S, Hosseini S, et al. (2019) Comparing duloxetine and pregabalin for treatment of pain and depression in women with fibromyalgia: an open-label randomized clinical trial. Daru 27(1):149-158.

24. Acet G, Kaya A, AkturkS, Akgol G (2017) A comparison of the effectiveness of amitriptilin and pregabalin treatment in fibromyalgia patients. North Clin Istanb 4(2): 151-159.

25. InformedHealth.org [Internet]. Cologne, Germany: Institute for Quality and Efficiency in Health Care (IQWiG); 2006-. Fibromyalgia: Complementary and alternative treatments.

26. Saeed SA, Cunningham K, Bloch RM (2019) Depression and Anxiety Disorders: Benefits of Exercise, Yoga, and Meditation. Am Fam Physician 99(10): 620-627.

27. Kwiatek R (2017) Treatment of fibromyalgia. Aust Prescr 40(5):179183.

28. Boger E, Ellis J, Latter S, Foster C, Kennedy A, et al. (2015) SelfManagement and Self-Management Support Outcomes: A Systematic Review and Mixed Research Synthesis of Stakeholder Views. PLoS One 10(7): e0130990.

29. Schmidt-Wilcke T, Diers M (2017) New Insights into the Pathophysiology and Treatment of Fibromyalgia. Biomedicines 5(2) pii: E22.

30. Kia S, Choy E (2017) Update on Treatment Guideline in Fibromyalgia Syndrome with Focus on Pharmacology. Biomedicines. 5(2). pii: E20.

31. Informed Health.org [Internet]. Cologne, Germany: Institute for Quality and Efficiency in Health Care (IQWiG) 2006-. Medication for the treatment of fibromyalgia. (2018)

32. Derry S, Wiffen PJ, Häuser W, Mücke M, Tölle TR et al. (2017) Oral nonsteroidal anti-inflammatory drugs for fibromyalgia in adults. Cochrane Database Syst Rev 3: CD012332.

33. Peng X, Robinson RL, Mease P, Kroenke K, Williams DA, et al. (2015) Long-term evaluation of opioid treatment in fibromyalgia. Clin J Pain 31(1): 7-13.
34. Stockings E, Campbell G, Hall WD, Nielsen S, Zagic D, et al. (2018) Cannabis and cannabinoids for the treatment of people with chronic noncancer pain conditions: a systematic review and meta-analysis of controlled and observational studies. Pain 159(10): 1932-1954.

35. Sagy I, Bar-Lev Schleider L, Abu-Shakra M, Novack V (2019) Safety and Efficacy of Medical Cannabis in Fibromyalgia. J Clin Med 8(6) pii: E807.

36. Van de Donk T, Niesters M, Kowal MA, Olofsen E, Dahan A, et al. (2019) An experimental randomized study on the analgesic effects of pharmaceutical-grade cannabis in chronic pain patients with fibromyalgia. Pain 160(4): 860-869.

37. Del Giorno R, Skaper S, Paladini A, Varrassi G, Coaccioli S (2015) Palmitoylethanolamide in Fibromyalgia: Results from Prospective and Retrospective Observational Studies. Pain Ther 4(2): 169-178.

38. Coskun Benlidayi I (2019) Role of inflammation in the pathogenesis and treatment of fibromyalgia. Rheumatol Int 39(5): 781-791.

39. Schweiger V, Martini A, Bellamoli P, Donadello K, Schievano C, et al. (2019) Ultramicronized Palmitoylethanolamide (um-PEA) as Add-on Treatment in Fibromyalgia Syndrome (FMS): Retrospective Observational Study on 407 Patients. CNS Neurol Disord Drug Targets 18(4): 326-333.

40. Mist S, Wright C, Jones KD, Carson JW, Shih J (2010) Traditional Chinese Medicine for Fibromyalgia. Pract Pain Manag 10(7).

41. Ali A, McCarthy PL (2014) Complementary and integrative methods in fibromyalgia. Pediatr Rev 35(12): 510-8.

42. Perry R, Leach V, Davies P, Penfold C, Ness A, et al. (2017) An overview of systematic reviews of complementary and alternative therapies for fibromyalgia using both AMSTAR and ROBIS as quality assessment tools. Syst Rev 6(1): 97.

43. Mahjoub F, Salari R, Noras MR, Yousefi M (2017) Are Traditional Remedies Useful in Management of Fibromyalgia and Chronic Fatigue Syndrome? A Review Study. J Evid Based Complementary Altern Med 22(4): 1011-1016.

44. Habib G, Avisar I (2018) The Consumption of Cannabis by Fibromyalgia Patients in Israel. Pain Res Treat.

45. Vučković S, Srebro D, Vujović KS, Vučetić Č, Prostran M (2018) Cannabinoids and Pain: New Insights From Old Molecules. Front Pharmacol 9: 1259.

46. Wang C, Schmid CH, Fielding RA, Harvey WF, Reid KF, et al. (2018) Effect of tai chi versus aerobic exercise for fibromyalgia: comparative effectiveness randomized controlled trial. BMJ 360: k851.

47. Zou L, Yeung A, Li C, Wei GX, Chen KW, et al. (2018) Effects of Meditative Movements on Major Depressive Disorder: A Systematic Review and Meta-Analysis of Randomized Controlled Trials. J Clin Med 7(8) pii: E195.

48. Sawynok J, Lynch ME (2017) Qigong and Fibromyalgia circa 2017. Medicines (Basel) 4(2) pii: E37.

49. Wang X, Li P, Pan C, Dai L, Wu Y, et al. (2019) The Effect of Mind-Body Therapies on Insomnia: A Systematic Review and Meta-Analysis. Evid Based Complement Alternat Med.

50. Silva AR, Bernardo A, Costa J, Cardoso A, Santos P, et al. (2019) Dietary interventions in fibromyalgia: a systematic review. Ann Med 51(sup1): 2-14.

51. Marum AP, Moreira C, Saraiva F, Tomas-Carus P, Sousa-Guerreiro C (2016) A low fermentable oligo-di-mono saccharides and polyols (FODMAP) diet reduced pain and improved daily life in fibromyalgia patients. Scand J Pain 13: 166-172.

52. Marum AP, Moreira C, Tomas-Carus P, Saraiva F, Guerreiro CS (2017) A low fermentable oligo-di-monosaccharides and polyols (FODMAP) diet is a balanced therapy for fibromyalgia with nutritional and symptomatic benefits. Nutr Hosp 34(3): 667-674.

53. Lattanzio SM, Imbesi F (2018) Fibromyalgia Syndrome: A Case Report on Controlled Remission of Symptoms by a Dietary Strategy. Front Med (Lausanne) 5: 94.

54. Glombiewski JA, Bernardy K, Häuser W (2013) Efficacy of EMG- and EEG-Biofeedback in Fibromyalgia Syndrome: A Meta-Analysis and 
a Systematic Review of Randomized Controlled Trials. Evid Based Complement Alternat Med 2013: 962741.

55. Goldway N, Ablin J, Lubin O, Zamir Y, Keynan JN, et al. (2019) Volitional limbic neuromodulation exerts a beneficial clinical effect on Fibromyalgia. Neuroimage 186: 758-770.

56. Barbosa-Torres C, Cubo-Delgado S, Bermejo-García ML, Vicente-Castro F (2019) Neurofeedback to improve attention, chronic pain, and quality of life in patients with fibromyalgia. Aten Primaria 51(5): 316-317.

57. Kayiran S, Dursun E, Dursun N, Ermutlu N, Karamürsel S (2010) Neurofeedback intervention in fibromyalgia syndrome; a randomized, controlled, rater blind clinical trial. Appl Psychophysiol Biofeedback 35(4): 293-302.

58. Zabihiyeganeh M, Vafaee Afshar S, Amini Kadijani A, Jafari D, Bagherifard A, et al. (2019) The effect of cognitive behavioral therapy on the circulating proinflammatory cytokines of fibromyalgia patients: A pilot controlled clinical trial. Gen Hosp Psychiatry 57: 23-28.

59. Informed Health.org [Internet]. Cologne, Germany: Institute for Quality and Efficiency in Health Care (IQWiG) 2006-(2018) Fibromyalgia: Multimodal pain management and cognitive behavioral therapy.

60. Mc Crae CS, Williams J, Roditi D, Anderson R, Mundt JM, et al. (2019) Cognitive behavioral treatments for insomnia and pain in adults with comorbid chronic insomnia and fibromyalgia: clinical outcomes from the SPIN randomized controlled trial. Sleep 42 (3).

61. Aman MM, Jason Yong R, Kaye AD, Urman RD (2018) Evidence-Based Non-Pharmacological Therapies for Fibromyalgia. Curr Pain Headache Rep 22(5): 33.

62. Mc Crae CS, Mundt JM, Curtis AF, Craggs JG, O Shea AM, et al. (2018) Gray Matter Changes Following Cognitive Behavioral Therapy for Patients with Comorbid Fibromyalgia and Insomnia: A Pilot Study. J Clin Sleep Med 14(9): 1595-1603.

63. Kashikar-Zuck S, Black WR, Pfeiffer M, Peugh J, Williams SE, et al. (2018) Pilot Randomized Trial of Integrated Cognitive-Behavioral Therapy and Neuromuscular Training for Juvenile Fibromyalgia: The FIT Teens Program. J Pain 19(9): 1049-1062.

64. Onieva-Zafra MD, Parra-Fernández ML, Fernandez-Martinez E (2019) Benefits of a Home Treatment Program Using Guided Imagery Relaxation Based on Audio Recordings for People with Fibromyalgia. Holist Nurs Pract 33(2): 111-120.

65. Onieva-Zafra MD, García LH, Del Valle MG (2015) Effectiveness of guided imagery relaxation on levels of pain and depression in patients diagnosed with fibromyalgia. Holist Nurs Pract 29(1): 13-21.

66. Giacobbi PR, Stabler ME, Stewart J, Jaeschke AM, Siebert JL, et al. (2015) Guided Imagery for Arthritis and Other Rheumatic Diseases: A Systematic Review of Randomized Controlled Trials. Pain Manag Nurs 16(5): 792-803.

67. Menzies V, Lyon DE, Elswick RK, McCain NL, Gray DP (2014) Effects of guided imagery on biobehavioral factors in women with fibromyalgia. J Behav Med 37(1): 70-80.

68. Claes N, Vlaeyen JWS, Lauwerier E, Meulders M, Crombez G (2018) Goal conflict in chronic pain: day reconstruction method. Peer J 6: e5272.

69. Martínez MP, Sánchez AI, Miró E, Medina A, Lami MJ (2011) The relationship between the fear-avoidance model of pain and personality traits in fibromyalgia patients. J Clin Psychol Med Settings 18(4): 380391.

70. Cohen H (2017) Controversies and challenges in fibromyalgia: a review and a proposal. Ther Adv Musculoskelet Dis 9(5): 115-127.

71. Palstam A, Larsson A, Löfgren M, Ernberg M, Bjersing J, et al. (2016) Decrease of fear avoidance beliefs following person-centered progressive resistance exercise contributes to reduced pain disability in women with fibromyalgia: secondary exploratory analyses from a randomized controlled trial. Arthritis Res Ther 18(1): 116.

72. Mohiuddin AK Pharmacy \& Pharmacology. International Journal 1(1): 27-95.
73. Wicksell RK, Kemani M, Jensen K, Kosek E, Kadetoff D, et al. (2013) Acceptance and commitment therapy for fibromyalgia: a randomized controlled trial. Eur J Pain 17(4): 599-611.

74. Simister HD, Tkachuk GA, Shay BL, Vincent N, Pear JJ, et al. (2018) Randomized Controlled Trial of Online Acceptance and Commitment Therapy for Fibromyalgia. J Pain 19(7): 741-753.

75. Luciano JV, Guallar JA, Aguado J, López-Del-Hoyo Y, Olivan B, et al. (2014) Effectiveness of group acceptance and commitment therapy for fibromyalgia: a 6-month randomized controlled trial (EFFIGACT study). Pain 155(4): 693-702.

76. Feliu-Soler A, Montesinos F, Gutiérrez-Martínez 0, Scott W, McCracken LM, et al. (2018) Current status of acceptance and commitment therapy for chronic pain: a narrative review. J Pain Res 11: 2145-2159.

77. Mior S (2001) Exercise in the treatment of chronic pain. Clin J Pain 17(4 Suppl): S77-85.

78. Bjersing JL, Larsson A, Palstam A, Ernberg M, Bileviciute-Ljungar I, et al. (2017) Benefits of resistance exercise in lean women with fibromyalgia: involvement of IGF-1 and leptin. BMC Musculoskelet Disord 18(1): 106.

79. Ericsson A, Palstam A, Larsson A, Löfgren M, Bileviciute-Ljungar I, et al. (2016) Resistance exercise improves physical fatigue in women with fibromyalgia: a randomized controlled trial. Arthritis Res Ther 18: 176.

80. Álvarez-Gallardo IC, Bidonde J, Busch A, Westby M, Kenny GP, et al. (2019) Therapeutic validity of exercise interventions in the management of fibromyalgia. J Sports Med Phys Fitness 59(5): 828-838.

81. Bidonde J, Busch AJ, Schachter CL, Webber SC, Musselman KE, et al. (2019) Mixed exercise training for adults with fibromyalgia. Cochrane Database Syst Rev 5: CD013340.

82. Bidonde J, Busch AJ, Schachter CL, Overend TJ, Kim SY, et al. (2017) Aerobic exercise training for adults with fibromyalgia. Cochrane Database Syst Rev 6: CD012700.

83. Bidonde J, Busch AJ, Van der Spuy I, Tupper S, Kim SY, et al. (2017) Whole body vibration exercise training for fibromyalgia. Cochrane Database Syst Rev 9: CD011755.

84. Gimigliano F (2019) Is whole body vibration exercise training effective and safe in fibromyalgia patients? A Cochrane Review summary with commentary. J Musculoskelet Neuronal Interact 19(2): 133-135.

85. Pujol J, Ramos-López D, Blanco-Hinojo L, Pujol G, Ortiz H, et al. (2019) Testing the effects of gentle vibrotactile stimulation on symptom relief in fibromyalgia. Arthritis Res Ther 21(1): 148.

86. Dong Y, Wang W, Zheng J, Chen S, Qiao J, et al. (2019) Whole Body Vibration Exercise for Chronic Musculoskeletal Pain: a Systematic Review and Meta-analysis of Randomized Controlled Trials. Arch Phys Med Rehabil

87. Zhang XC, Chen H, Xu WT, Song YY, Gu YH, et al. (2019) Acupuncture therapy for fibromyalgia: a systematic review and meta-analysis of randomized controlled trials. J Pain Res 12: 527-542.

88. Mist SD, Jones KD (2018) Randomized Controlled Trial of Acupuncture for Women with Fibromyalgia: Group Acupuncture with Traditional Chinese Medicine Diagnosis-Based Point Selection. Pain Med 19(9): 1862-1871.

89. Yang B, Yi G, Hong W, Bo C, Wang Z, et al. (2014) Efficacy of acupuncture on fibromyalgia syndrome: a meta-analysis. J Tradit Chin Med 34(4): 381-91.

90. Deare JC, Zheng Z, Xue CC, Liu JP, Shang J, et al. (2013) Acupuncture for treating fibromyalgia. Cochrane Database Syst Rev (5): CD007070.

91. Ozen S, Saracgil Cosar SN, Cabioglu MT, Cetin N (2019) A Comparison of Physical Therapy Modalities Versus Acupuncture in the Treatment of Fibromyalgia Syndrome: A Pilot Study. J Altern Complement Med 25(3): 296-304.

92. Karatay S, Okur SC, Uzkeser H, Yildirim K, Akcay F (2018) Effects of Acupuncture Treatment on Fibromyalgia Symptoms, Serotonin, and Substance P Levels: A Randomized Sham and Placebo-Controlled Clinical Trial. Pain Med 19(3): 615-628. 
93. Atzeni F, Casale R, Alciati A, Masala IF, Batticciotto A, et al. (2019) Hyperbaric oxygen treatment of fibromyalgia: a prospective observational clinical study. Clin Exp Rheumatol 116(1): 63-69.

94. El-Shewy KM, Kunbaz A, Gad MM, Al-Husseini MJ, Saad AM, et al. (2019) Hyperbaric oxygen and aerobic exercise in the long-term treatment of fibromyalgia: A narrative review. Biomed Pharmacother 109: 629-638.

95. Casale R, Boccia G, Symeonidou Z, Atzeni F, Batticciotto A, et al. (2019) Neuromuscular efficiency in fibromyalgia is improved by hyperbaric oxygen therapy: looking inside muscles by means of surface electromyography. Clin Exp Rheumatol Suppl 116(1): 75-80.

96. Tirelli U, Cirrito C, Pavanello M, Piasentin C, Lleshi A, et al. (2019) Ozone therapy in 65 patients with fibromyalgia: an effective therapy. Eur Rev Med Pharmacol Sci 23(4): 1786-1788.

97. Jackson W, Zale EL, Berman SJ, Malacarne A, Lapidow A, et al. (2019) Physical functioning and mindfulness skills training in chronic pain: a systematic review. J Pain Res 12: 179-189.

98. Pleman B, Park M, Han X, Price LL, Bannuru RR, et al. (2019) Mindfulness is associated with psychological health and moderates the impact of fibromyalgia. Clin Rheumatol 38(6): 1737-1745.

99. Adler-Neal AL, Zeidan F (2017) Mindfulness Meditation for Fibromyalgia: Mechanistic and Clinical Considerations. Curr Rheumatol Rep 19(9): 59.

100. Kline JA, Fisher MA, Pettit KL, Linville CT, Beck AM (2019) Controlled clinical trial of canine therapy versus usual care to reduce patient anxiety in the emergency department. PLoS One 14(1): e0209232.

101. Li YH, Wang FY, Feng CQ Yang XF, Sun YH (2014) Massage therapy for fibromyalgia: a systematic review and meta-analysis of randomized controlled trials. PLoS One 9(2): e89304.

102. Kalichman L (2010) Massage therapy for fibromyalgia symptoms. Rheumatol Int 30(9): 1151-1157.

103. De Oliveira FR, Visnardi Gonçalves LC, Borghi F, Da Silva LGRV, Gomes AE, et al. (2018) Massage therapy in cortisol circadian rhythm, pain intensity, perceived stress index and quality of life of fibromyalgia syndrome patients. Complement Ther Clin Pract 30: 85-90.

104. Honda Y, Sakamoto J, Hamaue Y, Kataoka H, Kondo Y, et al. (2018) Effects of Physical-Agent Pain Relief Modalities for Fibromyalgia Patients: A Systematic Review and Meta-Analysis of Randomized Controlled Trials. Pain Res Manag.

105. Dailey DL, Rakel BA, Vance CG, Liebano RE, Amrit AS, et al. (2013) Transcutaneous electrical nerve stimulation reduces pain, fatigue and hyperalgesia while restoring central inhibition in primary fibromyalgia. Pain 154(11): 2554-2562.

106. Johnson MI, Claydon LS, Herbison GP, Jones G, Paley CA (2017) Transcutaneous electrical nerve stimulation (TENS) for fibromyalgia in adults. Cochrane Database Syst Rev 10: CD012172.

107. Mutlu B, Paker N, Bugdayci D, Tekdos D, Kesiktas N (2013) Efficacy of supervised exercise combined with transcutaneous electrical nerve stimulation in women with fibromyalgia: a prospective controlled study. Rheumatol Int 33(3): 649-655.

108. Matsumoto S, Shimodozono M, Etoh S, Miyata R, Kawahira K (2011) Effects of thermal therapy combining sauna therapy and underwater exercise in patients with fibromyalgia. Complement Ther Clin Pract 17(3): 162-166

109. Guidelli GM, Tenti S, De Nobili E, Fioravanti A (2012) Fibromyalgia syndrome and spa therapy: myth or reality? Clin Med Insights Arthritis Musculoskelet Disord 5: 19-26.

110. Nascimento SS, Araújo AA, Brito RG, Serafini MR, Menezes PP, et al. (2014) Cyclodextrin-complexed Ocimum basilicum leaves essential oil increases Fos protein expression in the central nervous system and produce an antihyperalgesic effect in animal models for fibromyalgia. Int J Mol Sci 16(1): 547-563.

111. Casanueva B, Rodero B, Quintial C, Llorca J, González-Gay MA (2013) Short-term efficacy of topical capsaicin therapy in severely affected fibromyalgia patients. Rheumatol Int 33(10): 2665-2670.

112. Demirbağ B, Erci B (2012) The effects of sleep and touch therapy on symptoms of fibromyalgia and depression. Iran J Public Health 41(11): 44-53.

113. (2008) Understanding fibromyalgia and its related disorders. Prim Care Companion J Clin Psychiatry. 10(2): 133-144.

114. Ernst E (2009) Chiropractic treatment for fibromyalgia: a systematic review. Clin Rheumatol 28(10): 1175-1178.

115. Schneider M, Vernon H, Ko G, Lawson G, Perera J (2009) Chiropractic management of fibromyalgia syndrome: a systematic review of the literature. J Manipulative Physiol Ther 32(1): 25-40.

116. Choy EH (2015) The role of sleep in pain and fibromyalgia. Nat Rev Rheumatol 11(9): 513-520.

117. Picard LM, Bartel LR, Gordon AS, Cepo D, Wu Q, et al. (2014) Music as a sleep aid in fibromyalgia. Pain Res Manag 19(2): 97-101.

118. Shereen Algergawy (2018) Musical therapy as a new strategy for pain in fibromyalgia, Rheumatology, 57(suppl_3).

119. Winkelmann A, Bork H, Brückle W, Dexl C, Heldmann P, et al. (2017) Physiotherapy, occupational therapy and physical therapy in fibromyalgia syndrome: Updated guidelines 2017 and overview of systematic review articles. Schmerz 31(3): 255-265.

120. Andrade A, De Azevedo Klumb Steffens R, Sieczkowska SM, Peyré Tartaruga LA, Torres Vilarino G (2018) A systematic review of the effects of strength training in patients with fibromyalgia: clinical outcomes and design considerations. Adv Rheumatol 58(1): 36.

121. Paolucci T, Baldari C, Di Franco M, Didona D, Reis V, et al. (2016) A New Rehabilitation Tool in Fibromyalgia: The Effects of Perceptive Rehabilitation on Pain and Function in a Clinical Randomized Controlled Trial. Evid Based Complement Alternat Med 2016: 7574589.

122. Roitenberg N, Shoshana A (2019) Physiotherapists accounts of fibromyalgia: role-uncertainty and professional shortcomings. Disabil Rehabil 30: 1-8.

123. García-Ríos MC, Navarro-Ledesma S, Tapia-Haro RM, Toledano-Moreno S, Casas-Barragán A, Et al. (2019) Effectiveness of health education in patients with fibromyalgia: a systematic review. Eur J Phys Rehabil Med 55(2): 301-313. 